\title{
LOS VINOS IBÉRICOS EN ROMA \\ (Y OSTIA) EN EL MEDIO IMPERIO \\ (SIGLO II - PRINCIPIOS DEL III D. C.). \\ ANÁLISIS Y REVISIONES DE DATOS
}

\author{
Edoardo Radaelli*
}

\begin{abstract}
The excavations in the building known as the Terme di Elagabalo in Rome revealed large amounts of fragments. The amounts of Iberian wine-amphorae found in the Middle Imperial contexts of this site $\left(2^{\text {nd }}-\right.$ early $3^{\text {rd }}$ centuries AD) will be added to those found in other excavations carried out in Rome and Ostia in order to ponder over their presence in both cities during this period. Also, ancient sources will be analyzed so as to identify the quality of these wines (including also the defrutum), leading to a reflection (with theories derived from social sciences) regarding their consumers.
\end{abstract}

Keywords: amphoras, Iberia, wine, commerce, consumption.

Palabras claves: ánforas, Iberia, vino, comercio, consumo.

\footnotetext{
* The University of Southampton, Faculty of Humanities, Department of Archaeology, Avenue Campus, Southampton, SO17 1BF, United Kingdom; Sapienza - Università di Roma, Facoltà di Lettere e Filosofia, Dipartimento di Scienze dell'Antichità, Piazzale Aldo Moro 5, 00185 Roma, Italia, edoardoradaelli@hotmail.it.
} 


\section{Introducción}

Los datos inéditos sobre las ánforas halladas en las excavaciones estratigráficas, entre 2007 y 2013 por el Departamento de Ciencias de la Antigüedad de la Sapienza - Universidad de Roma en el lugar usualmente conocido como las Termas de Heliogábalo en Roma ${ }^{1}$, han sido la base para una reflexión sobre la presencia de las ánforas vinarias, de origen ibérico, durante el Medio Imperio (siglo II -principios del III d. C.) en Roma y también en Ostia², lugar este último que siempre ha servido para comparar y comprender el comercio de la metrópoli ${ }^{3}$. Estos nuevos datos se han añadido a aquellos procedentes de unas excavaciones de las dos ciudades ${ }^{4}$, actualizándolos con cálculos basados en los volúmenes (en litros) contenidos en cada forma anfórica. El estudio presente se dividirá cronológicamente en fases cuya nomenclatura, como es común, se basa en los nombres de los emperadores (épocas trajanea, adrianea, antonina y severiana) $)^{5}$. No obstante, es posible que surjan algunos problemas si se intenta utilizar las ánforas para comprender el comercio romano (cfr. Radaelli, 2018b: 246, nota 3), así como aquello

1 Las descripciones de todos los edificios resultantes de las excavaciones estratigráficas son visibles en Saguì y Cante, 2015, con bibliografía. Los fragmentos anfóricos de este lugar son casi por completo inéditos, excepto los publicados en Radaelli, 2013; 2016; 2017; 2018a; 2018b.

2 Para las referencias de los sitios considerados en ambas ciudades cfr. Radaelli, 2017: 1043.

3 Este estudio sintético ofrece datos más ampliamente estudiados en la tesis de PhD conseguida en la Universidad de Southampton (UK). Quisiera agradecer al profesor S. J. Keay, a la profesora C. Panella, a la profesora L. Saguì y también a Alicia Moreno Esteban y a Clara Ramos Bullón que ambas han revisado el español de este texto.

4 Algunos sitios en Roma y en Ostia no son incluidos en este estudio porque sus publicaciones tienen problemas en las cuantificaciones o en la atribución en sus fases cronológicas.

5 Época trajanea - principios del II siglo d. C.; época adrianea - segunda y tercera década del II siglo d. C.; época antonina - finales de la primera mitad y segunda mitad del II siglo d. C.; época severiana - finales del II y principios del III siglo d. C. 
que se refiere a la imposibilidad de determinar con seguridad si las ánforas descubiertas en las excavaciones puedan ser realmente representativas para una comprensión no sólo del general abastecimiento de alimentos ${ }^{6}$, sobre el consumo de los mismos, habida cuenta de que el hallazgo se compone de fragmentos y se han hallado en zonas de desecho y no en lugares de uso 7 . A pesar de los problemas, las ánforas serán consideradas aquí por sus funciones primarias, es decir, contenedores comerciales. Los gráficos ofrecidos en este estudio incluirán todos los litros contenidos por todas las formas anfóricas descubiertas, menos aquellas que son residuales (o intrusivas) que no serán incluidas, ya que no pueden proporcionar información de cambios sobre las cantidades efectivas. De igual manera, los cálculos no incluirán los litros de las formas que no se han encontrado íntegras, porque no se han podido determinar sus volúmenes con seguridad. Los volúmenes ofrecidos están recogidos en publicaciones recientes o han sido calculados geométricamente a partir de las imágenes de objetos íntegros ${ }^{8}$. En cambio, el número de ánforas se ha calculado utilizando metodologías relativas a las llamadas NMI (Número Mínimo de Individuos), su calibración NTI (Número Tipológico de Individuos) y EVE (Equivalente de Vasos Estimados; para estas metodologías cfr. Radaelli, 2017: 1043

6 Algunos estudiosos opinan que las ánforas no pueden ser el inicio que sirva para comprender el comercio y la historia política y económica del mundo romano, negando claramente la validez de cualquier estudio que quiera reconstruir el abastecimiento de alimentos (Peña, 2007: 345).

7 La evidencia de las publicaciones es endeble porque raramente se han descubierto ánforas en las fases de uso de los edificios. Considerar los restos en basureros como reflejo del consumo puede no ser concluyente: los lugares en que se consumían los alimentos contenidos podrían ser diferentes de aquellos donde los contenedores se desechaban.

8 Se han dividido aquellas imágenes en partes que podían ser asimiladas a formas geométricas: cilindros (volumen $=\pi \mathrm{R}^{2} \mathrm{~h}$ ), conos (volumen $\left.=1 / 3 \pi R^{2} h\right)$, conos truncados (volumen $=1 / 3 \pi h\left(R^{2}+r^{2}+R r\right)$ o esferas (volumen $=4 / 3 \pi R^{3}$ ). Al final, se han añadido los volúmenes de todas estas divisiones para llegar a un volumen aproximado del ánfora entera en $\mathrm{cm}^{3}$, después convertido en litros $\left(\mathrm{mil} \mathrm{cm}^{3}=1\right.$ litro). 
con bibliografía). Respecto al espacio, las ánforas descubiertas no serán tratadas difusamente (solo las ibéricas se pueden ver en la fig. $1^{9}$ ), sino que serán cuantificados los porcentajes que se basarán en los cálculos derivados de volúmenes totales en litros de las ánforas halladas. Por supuesto, estos datos no aspiran a ser exhaustivos, porque solo consideran las ánforas documentadas a través de un análisis directo (aquellas en las Termas de Heliogábalo) y de publicaciones (en otros lugares), por lo que podrán ser modificados por nuevos hallazgos y nuevas publicaciones.

\section{2.}

\section{Los vinos ibéricos}

Junto al aceite y a las salsas de pescado (sobre las ánforas que contenían salsas de pescado de la Península Ibérica en Roma y Ostia cfr. Radaelli, 2017), principales productos de esta tierra que la hicieron famosa durante la época romana, la Península Ibérica produjo también vino que era comercializado en Roma a través de unas ánforas (fig. 1).

La mayoría de las formas halladas son imitaciones de contenedores itálicos, como las Pascual 1 (cfr. López Mullor, Martín Menédez, 2008: 698-701), la Tarraconense 1 (cfr. López Mullor, Martín Menédez, 2008: 694-697) y especialmente las Dressel 2-4 (sea de la Baetica, sea de la Tarraconensis), con algunas excepciones como las Oberaden 74 y las Dressel 28 (y sus variantes tardías) que imitaban formas de la Galia y las Haltern 70 fabricadas desde la época augustea para contener el defrutum bético (cfr. más bajo) ${ }^{10}$.

9 Para la descripción, la división tipológica, la producción y la distribución de la mayoría de esas formas cfr. Rizzo, 2014a, 99-154.

10 No se consideran aquí las formas llamadas "polivalentes" como las Dressel 7-11, las Beltrán IIA o IIB que habían podido contener también vino, no sólo las salsas de pescado que deberían ser sus contenidos primarios (cfr. García Vargas, 2004a: 509-510 y 2004b: 123-127, ambos con referencias). 


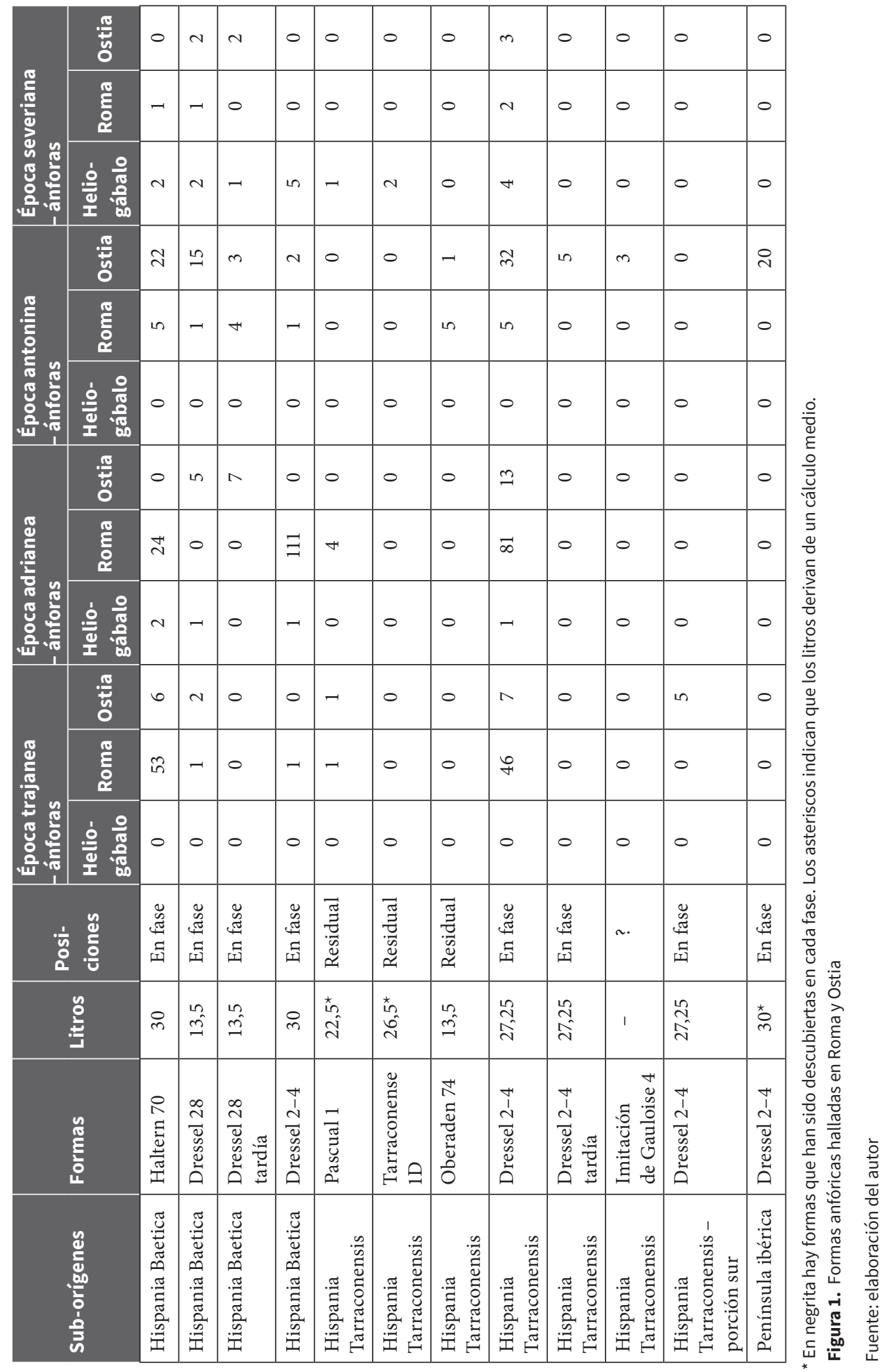


Pocos litros de vinos ibéricos llegaron a ambas ciudades (especialmente en Roma) y durante todas las fases cronológicas consideradas. Este dato solo parcialmente refleja una generalizada escasez de fuentes antiguas que hablan de estos dos orígenes.

Estrabón (III, 2, 6), citando Posidonius, informa que ya en el 70 a. C. la Hispania Baetica exportaba vino, mientras que Varón (I, 8, 1) menciona la producción de vino en esta provincia. Un siglo después, Columela (I, pref. 20) ofrece otros datos, como que su tío parece que hubiera tenido viñas ${ }^{11}$. Las monedas (Étienne, Mayet, 2000: 61-66), algunos alfares anfóricos (García Vargas, 2004b: 128-130) y fuentes arábigas confirman esta producción (Étienne, Mayet, 2000: 71-72). Los tituli picti informan también de producciones, como el Gaditanum o hipotéticamente el Has(tense) (Rizzo, 2014b: 403). Todas estas fuentes no explicitan la calidad de estos vinos. Por esta razón, la hipótesis declarada por Étienne (1975: 312, n. 60) y aceptada por Tchernia (1986: 175-176) que consideran estos vinos unos de los peores vinos romanos ${ }^{12} \mathrm{o}$ aquella apuntada por García Vargas que describe una calidad medio baja (García Vargas, 2004a: 511-512). Ambas pueden explicar los bajos porcentajes de vinos originarios de Bética en Roma y en Ostia (fig. 3), que son aumentados solo por una presencia bastante amplia de defrutum ${ }^{13}$. Si ese producto puede ser asimilado al vino por su origen (Étienne, Mayet, 2000: 95 con biblio-

11 Brun, 2004: 281. El tío de Columela producía vino con un añadido de sal y agua de mar al mosto, después clarificándolo en el revoque, reforzándolo con el defrutum y saborizándolo con el fenogreco (Columela, XII, 21, 3-6) que lo convierte en el productor más laborioso de toda la Baetica (Columela V, 5, 15).

12 Ellos consideran la mención en Ovidio de la palabra "Hispano" (Ovidio, Ars Am., III, 645-646) que puede ser atribuida a la Baetica.

13 A pesar de la falta general de seguridad, la palabra defrutum puede haber definido un producto especial que derivaba del vino, creado con una reducción del mosto (Étienne y Mayet, 2000: 93; Carreras Monfort y Aguilera, 2004: 121-122) y con gran presencia de azúcar (Brun, 2003: 92). Plinio el Viejo (XIV, 80) ofrece una receta para crear el defrutum que es la misma mencionada por Columela (XII, 19,1 y 12) y diferente de aquella descrita por Paladio (XI, XVIII) que tiene proporciones diferentes. 
grafía que favorece esta hipótesis), el edicto de precios de Diocleciano lo clasificó entre los vinos reducidos mediante cocción y no entre los vinos alcohólicos (Giacchero, 1974: 2, 16; García Vargas, 2004a: 507). En efecto el defrutum era utilizado principalmente para otros usos como la conservación de aceitunas (Étienne, Mayet, 2000: 96 con una lista de tituli picti que las mencionan; Brun, 2003: 92 y nota 120; al contrario Carreras Monfort, Aguilera, 2004: 130 consideran aceitunas el contenido principal de las ánforas Haltern 70) y otra fruta (Étienne, Mayet, 2000: 97ł Carreras Monfort, Aguilera, 2004: 129 con una lista de usos derivados de fuentes antiguas) o en la medicina, la farmacopea, la cocina y para la alimentación de animales (Carreras Monfort, Aguilera, 2004: 130-131). Estas razones han inducido a una separación entre el defrutum y los otros vinos béticos (en la fig. 2). En Roma se observa una disminución constante del defrutum hasta la época severiana, cuando se hace patente la cantidad menor en litros. Este dato puede ser perfectamente explicado por la interrupción en la fabricación de sus contenedores a finales del siglo II d. C. (en cambio, Carreras Monfort, 2010: 204 ha defendido como fecha del fin de esa producción a principios del siglo II d. C.). De todos modos, hay que señalar que en Roma los vinos béticos son relativamente abundantes solamente durante la época adrianea. En cambio, en Ostia se nota una escasez generalizada, con la excepción de un pequeño aumento durante la época antonina (que puede ser reflejo de un crecimiento real en las importaciones en esta ciudad, o por el contrario el resultado de contextos específicos que se han estudiado en esta ciudad y que son datados durante esta época).

Al contrario, hay más menciones (sea en escritores antiguos, sea en inscripciones) sobre la Hispania Tarraconensis. Esta provincia era renombrada por una producción de dos vinos considerados de calidad por su elegantia (Plinio, XIV, 71; cfr. también Cerchiai Manodori Sagredo, 2013: 273): los de Tarraco (Silio Itálico, III, 369 y XV, 178; Marcial, XIII, 118; Floro, Vergilius orator an poeta, II, 8; cfr. también Revilla Calvo, 2008: 218-219 con referencias) y los de Lauro (Tituli picti: CIL XV, 4577-4579 y otros publicados por Étienne, Mayet, 2000: 105) que probablemente estaban destinados a una clientela que pertenecía a rangos sociales ni riquísimos, ni paupérrimos (Dell’Amico, Pallares, 2007: 66). 


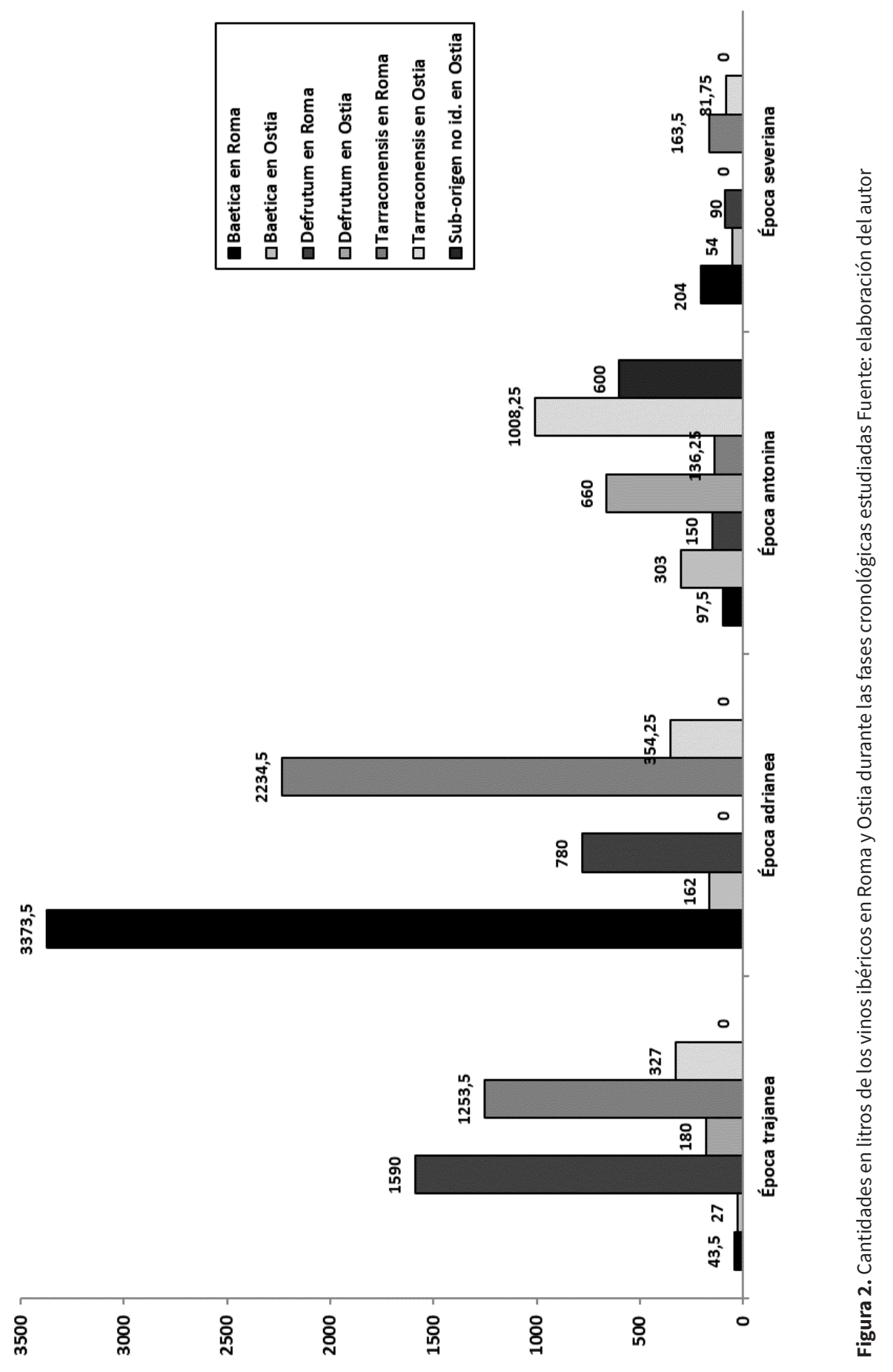


Esta provincia producía también dos vinos de calidad inferior que derivaban de una producción masiva y que estaban hipotéticamente directos a rangos sociales más bajos: de Saguntum (Juvenal, V, 29; Frontón, Ep. de eloquentia, I, 4; CIL XV, 2632; CIL II, 6254, 6; además Plinio el Joven, II, 13 y X, 28, 2 cita Voconius Romanus que tenía viñedos en esta región que también producían vino) y de Laetania (Plinio el Viejo, XIV, 71; Marcial, I, 26, 9-10 y VIII, 53, 6 ha estimado muy económicos esos vinos). Lamentablemente, las ánforas halladas en los contextos analizados no tienen inscripciones, así que es casi imposible determinar si contenían vinos de alta o baja calidad (Rizzo, 2014b: 403). Sin embargo, aunque sobre esta área haya un desconocimiento de las infraestructuras y un conocimiento parcial de los espacios productivos (Revilla Calvo, 2008: 191-214), además de pocos lugares de producción directa (Peña Cervantes, 2011/2012: 51), se han hallado unos alfares dedicados a la fabricación de ánforas Dressel 2-4 en Laetania (Dell'Amico, Pallares, 2007: 119-122). En consecuencia, es posible suponer que por lo menos algunos de los contenedores descubiertos en las dos ciudades objeto de este estudio, contuvieran vinos de segunda calidad, lo que no dificultaba las exportaciones a estas dos ciudades, a tenor de las cantidades, que probablemente fueran realizadas no solamente a través de las ánforas sino también de los dolia (Dell'Amico, Pallarés, 2007: 55-57, 60, 61-63, 65-66). Lo que también refleja la riqueza y el prestigio de las élites locales (Revilla Calvo, 2008: 220-223), que convirtieron estos vinos en bebidas reputadas como exóticas en los lugares donde eran exportadas (Bernal Casasola, 2008: 346). Las cantidades analizadas muestran que desde la época adrianea en Roma hay un decrecimiento drástico, mientras en Ostia este origen parece crecer hasta la época antonina cuando alcanza a un pico significativo en las cantidades de litros ${ }^{14}$.

14 Se han atribuido cinco ánforas halladas en Ostia en contextos datados en la época trajanea a una "zona sur" de esta provincia. Todavía no es posible determinar lo que esta denominación significa precisamente. 


\begin{tabular}{|c|c|c|c|c|c|c|c|c|c|}
\hline & & $i_{10}^{10}$ & so & $\hat{\hat{i}}$ & 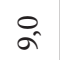 & $\vec{i}$ & $\underbrace{0}_{0}$ & $\stackrel{\vec{n}}{\sim}$ & $\stackrel{0}{n}$ \\
\hline & $\therefore$ & 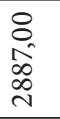 & $\begin{array}{l}8 \\
\text { \& } \\
\text { in }\end{array}$ & $\begin{array}{l}8 \\
0 \\
\infty \\
0 \\
0\end{array}$ & $\begin{array}{l}n \\
\hat{b} \\
i n\end{array}$ & 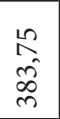 & 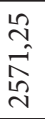 & 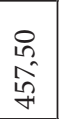 & $\begin{array}{l}\stackrel{n}{2} \\
\text { ŝt } \\
\end{array}$ \\
\hline & 。ั & 0 & 0 & 0 & 0 & 0 & $\stackrel{n}{=}$ & 0 & 0 \\
\hline & $\therefore$ & 0 & 0 & 0 & 0 & 0 & : & 0 & 0 \\
\hline & 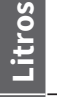 & $\stackrel{+}{i}$ & $i^{2}$ & $\hat{o}$ & రु & $\hat{0}$ & $\begin{array}{l}0 \\
i \\
i\end{array}$ & $\begin{array}{l}\infty \\
0 \\
0\end{array}$ & $\stackrel{n}{\rightarrow}$ \\
\hline 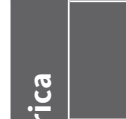 & $\circ^{\circ}$ & 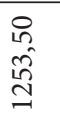 & $\begin{array}{l}\stackrel{8}{\mathrm{~N}} \\
\text { ì }\end{array}$ & $\begin{array}{l}\text { in } \\
\stackrel{n}{n} \\
\hat{N} \\
\hat{N}\end{array}$ & \begin{tabular}{l}
$\stackrel{n}{2}$ \\
\multirow{H}{n}{} \\
$m$
\end{tabular} & 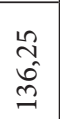 & 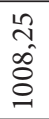 & 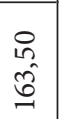 & $\stackrel{\substack{n \\
\infty}}{\infty}$ \\
\hline 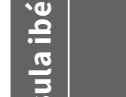 & 递 & $\vec{m}$ & $\stackrel{H}{n}$ & $\hat{\approx}$ & $\begin{array}{l}\infty \\
\hat{i}\end{array}$ & $\stackrel{+}{\pi}$ & $\stackrel{n}{i}$ & $\stackrel{n}{\rightarrow}$ & $\stackrel{\sim}{\approx}$ \\
\hline 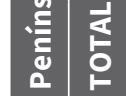 & $\circ^{\circ}$ & 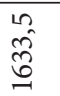 & $\begin{array}{l}\stackrel{0}{\hat{i}} \\
\text { in }\end{array}$ & $\begin{array}{l}\stackrel{n}{2} \\
\hat{n} \\
\Rightarrow\end{array}$ & $\begin{array}{l}0 \\
\hat{U}\end{array}$ & $\begin{array}{l}\stackrel{2}{2} \\
\stackrel{+}{N}\end{array}$ & $\begin{array}{l}0 \\
\hat{\delta} \\
\text { }\end{array}$ & $\begin{array}{l}0 \\
\text { ते } \\
\text { (n) }\end{array}$ & 욤 \\
\hline & o气 & 0 & 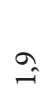 & 0 & $\hat{0}_{0}^{\infty}$ & 0 & 0 & 0 & $\stackrel{n}{\sim}$ \\
\hline$\frac{0}{2}$ & $0^{\circ}$ & 0 & ్ㅗㄱ & 0 & ஓे & 0 & 0 & 0 & 8 \\
\hline . & ơ & $\begin{array}{l}0 \\
\dot{m}\end{array}$ & $\hat{\underline{m}}$ & $\stackrel{0}{i}$ & $\overrightarrow{\hat{n}}$ & $\begin{array}{l}\vec{H} \\
\stackrel{0}{0} \\
\tilde{e}^{2}\end{array}$ & $\overrightarrow{\vec{v}}$ & $\hat{\tilde{n}}$ & $\begin{array}{l}0 \\
\text { ŝn }\end{array}$ \\
\hline 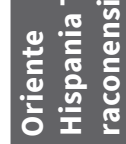 & $0^{\circ}$ & 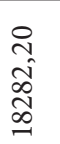 & $\begin{array}{l}\text { I } \\
\text { Na } \\
\infty \\
\infty\end{array}$ & 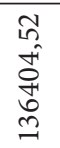 & 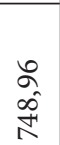 & $\begin{array}{l}\vec{m} \\
\overrightarrow{\hat{D}} \\
0\end{array}$ & $\begin{array}{l}\hat{N} \\
\hat{\alpha} \\
\infty \\
\infty \\
\infty\end{array}$ & $\begin{array}{l}\vec{m} \\
\overrightarrow{\hat{\sigma}} \\
\sigma\end{array}$ & \begin{tabular}{l} 
ดे \\
fิ \\
\multirow{\exists}{*}{}
\end{tabular} \\
\hline & 。气 & $\hat{0}$ & $\vec{f}$ & $=$ & $\stackrel{H}{+}$ & $\hat{0}$ & $\hat{f}$ & $\vec{\sigma}$ & $\stackrel{m}{=}$ \\
\hline 은 & $0^{\circ}$ & 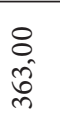 & $\begin{array}{l}8 \\
\stackrel{\hat{n}}{n} \\
\end{array}$ & $\begin{array}{l}\widetilde{\sigma} \\
\stackrel{N}{N} \\
\stackrel{N}{N}\end{array}$ & $\begin{array}{l}\text { in } \\
\text { dn } \\
\text { ñ }\end{array}$ & 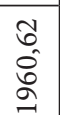 & 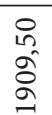 & 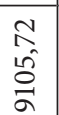 & 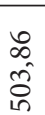 \\
\hline & ơ & $\stackrel{\leftrightarrow}{+}$ & $\stackrel{m}{\Rightarrow}$ & $\stackrel{\infty}{a}$ & $\begin{array}{l}\infty \\
\dot{0} \\
\hat{n}\end{array}$ & $\begin{array}{l}0 \\
\stackrel{-}{=}\end{array}$ & în & $\hat{\imath}$ & $\begin{array}{l}n \\
\hat{n}\end{array}$ \\
\hline हू & $0^{\circ}$ & 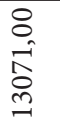 & \begin{tabular}{l}
8 \\
8 \\
0 \\
\multirow{1}{1}{}
\end{tabular} & 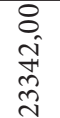 & $\begin{array}{l}\stackrel{8}{o} \\
\mathfrak{i} \\
\vec{\pi}\end{array}$ & 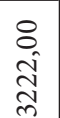 & 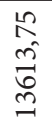 & 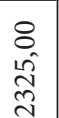 & $\begin{array}{l}8 \\
\text { \&ิ } \\
\text { İ }\end{array}$ \\
\hline & ơ & $\begin{array}{l}\stackrel{n}{2} \\
\hat{m}\end{array}$ & $\overrightarrow{\hat{n}}$ & ते & बे & $\hat{m}$ & $\begin{array}{l}0 \\
\vec{m}\end{array}$ & $\begin{array}{l}\infty \\
\hat{\beth}\end{array}$ & के \\
\hline$\Phi$ & $\circ^{\circ}$ & 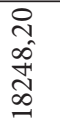 & \begin{tabular}{l}
$\tilde{N}$ \\
\multirow{2}{*}{} \\
$\infty$ \\
$\infty$
\end{tabular} & 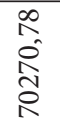 & 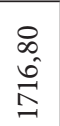 & $\begin{array}{l}\tilde{o} \\
\dot{0} \\
0 \\
0 \\
0\end{array}$ & 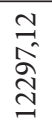 & 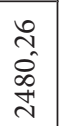 & $\begin{array}{l}\text { సิ } \\
\text { పే } \\
=\end{array}$ \\
\hline & & $\begin{array}{l}\tilde{\Xi} \\
\check{\mathscr{q}}\end{array}$ & $\stackrel{\overrightarrow{\tilde{B}}}{0}$ & $\begin{array}{l}\tilde{\Xi} \\
\tilde{0}\end{array}$ & $\stackrel{\overrightarrow{\tilde{H}}}{0}$ & $\begin{array}{l}\widetilde{\Xi} \\
\stackrel{0}{\simeq}\end{array}$ & $\stackrel{\vec{w}}{\tilde{m}}$ & 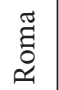 & 悉 \\
\hline 룰 은 & & & & & & & & & \\
\hline
\end{tabular}


Dos orígenes vinícolas diferentes a los ya referidos merecen una breve mención. El vino producido en la isla de Ibiza era exportado también a Roma, como atestigua una sola ánfora de la forma Ramón PE-25 (para su descripción, la división tipológica, el volumen en litros, la producción y la distribución cfr. Ramón Torres, 2008: 243-263 con referencias) que se ha descubierto en Via Marmorata (Bertoldi, 2011: 150, aunque este sea uno de los lugares no considerados aquí por los problemas de cuantificación y datación) ${ }^{15}$. La Lusitania también producía mucho vino ${ }^{16}$, aunque las ánforas vinarias originarias de esta provincia no hayan sido halladas ni en Roma ni en Ostia, porque probablemente este vino tuviera una distribución diferente (parcialmente local) o porque lo transportaban a estas ciudades a través de cupae (barriles) u orcas (Peña Cervantes, 2011/2012: 52) que nunca se han encontrado en las dos ciudades analizadas (Radaelli, 2018a). Además, en Ostia, durante la época antonina, hay también 600 litros contenidos en ánforas sin identificación de sus orígenes en la publicación.

La fig. 3 enseña todos los orígenes de los vinos (en litros) estudiados y sus porcentajes durante las cuatro épocas consideradas. Estos porcentajes reflejan todas las ánforas vinarias halladas en

15 El vino ebusitano tiene una larga historia, a partir de la expansión fenicia y era probablemente otro producto de calidad, como aquellos ya mencionados de Tarraconensis, que podía competir con los itálicos (Plinio, XIV, 71; cfr. también Brun, 2004: 261; en cambio Maurimon Ribas, 2009: 5-6, considera el mismo pasaje de Plinio como referente a Mallorca y Menorca). Cfr. también el reciente artículo de Marlière et al., 2016: 418-420 en que se han estudiado ánforas con grafiti post cocturam que sugieren el contenido específico de unas formas anfóricas de Ibiza (por lo menos en el contexto de uso que se ha descubierto).

16 Polibio (XXXIV, 8 = Ateneo, VIII, 330c) informa que desde el siglo II a. C. su vino era abundante y no demasiado caro, mientras Estrabón (III, 3, 1) solo menciona "buenos viñedos". Su calidad era probablemente mediocre u ordinaria (Étienne, Mayet, 2000: 21). Se han descubierto unos sitios de producción (Peña Cervantes, 2011/2012: 51-52), lo que confirma la fabricación de ánforas vinarias en esta provincia (Brun, 1997: 52-53 y bibliografía; 2004: 284-294). 
las excavaciones analizadas en las dos ciudades (estos datos y porcentajes son diferentes de los publicados en Radaelli, 2016, fig. 1B porque estos últimos no incluían los litros de defrutum que son aquí incluidos). Durante la época trajanea los vinos ibéricos llegan a un $5,5 \%$ en Roma y $8,7 \%$ en Ostia. Durante la época adrianea, incluso con un aumento de las cantidades, el porcentaje en Roma es reducido a un 2,7\%, mientras en Ostia se ve una disminución de las cantidades, aunque con un pequeño aumento porcentual. Durante la época antonina en Roma se observa una primera disminución drástica en los litros y porcentajes $(2,1 \%$ total de litros ibéricos), mientras que en Ostia se constata un aumento de los litros que todavía no está reflejado en el porcentaje que se ha reducido (6,6\% en total). En la época severiana hay una disminución generalizada de los litros (verosímilmente causada también por una escasez de los contextos que pertenecen a esta fase) que resulta en un pequeño aumento del porcentaje en Roma $(2,4 \%)$ y en una disminución en Ostia (3,0\%).

\section{3. \\ El vino y su consumo}

La base alimentaria romana consistía en cereales, vino y aceite. Estos tres alimentos -aunque las salsas de pescado pueden también ser añadidas a estos tres-, excepto los cereales, eran comercializados y transportados a través de ánforas. El vino siempre ha sido un producto muy importante porque se convirtió pronto en el producto más generalizado de la antigüedad: el vino era la bebida, la droga (por su efectos psicoactivos) y el medicamento más utilizado por muchas sociedades cuyas economías a menudo se basaban en él (Thurmond, 2006: 111). Durante la edad romana su importancia se incrementó, por lo que se cultivó la vid en casi todas las partes del Mediterráneo y el vino tuvo funciones significativas y variadas (religiosas, militares, políticas, familiares y personales). Una de las razones de su incremento productivo y éxito está relacionada con las cuestiones sociales que el vino 
siempre tenía y que mantiene: define y articula las relaciones humanas asumiendo la capacidad de ser un elemento de cohesión social (Radaelli, 2018b: 250 con bibliografía). El vino es también mencionado por muchísimos autores antiguos, de manera que se convirtió en el producto más presente en la literatura griega y latina dentro de la categoría de alimentos básicos a los que pertenece y que han sido mencionados anteriormente. No obstante, el vino como alimento esencial parece haber sido uno de los productos excluidos de la interferencia directa del Estado romano. Se puede suponer que interviniera de alguna manera en el control y abastecimiento de todos los productos que llegaban a la Capital del Imperio ${ }^{17}$. No obstante, el vino (y el alcohol contenido en él) conllevaría a un incremento de calorías; su consumo no estaba ligado solo a las necesidades biológicas ya que también tenía que satisfacer necesidades culturales y definir los límites entre rangos sociales (cfr. Radaelli, 2018b: 250-251 con bibliografía). El alcohol era un agente de cohesión social que podía incrementar el placer de los convivia (el ambiente en que el vino era habitualmente consumido) con euforia y alegría que eran siempre bien apreciadas en aquellas atmósferas (Cerchiai Manodori Sagredo, 2013: 317-318). Por otra parte, es un hecho bien conocido que todos los romanos bebían muchísimo vino, especialmente durante el periodo imperial. Lo bebían tanto en las comidas, como con la voluntad de superar el límite para emborracharse (cfr. Cerchiai Manodori Sagredo, 2013: 199-219, 319-323) o colapsarse (D’Arms, 1995: 312-314), aunque evidentemente no conocieran el concepto actual de alcoholismo (D’Arms, 1995: 316-317). Además, algunos estudiosos han intentado cuantificar los litros de vino bebidos por la población de Roma y las cantidades resultantes de estos cálculos son siempre muy amplias ${ }^{18}$. Todo esto sin contar los litros que

17 Comunicación personal de la profesora Clementina Panella.

18 Tchernia (1986: 21-27; 2011b: 257) sugirió una cifra entre 1.170.000 y 1.460.000 hectolitros (para una población de 800 mil personas) y entre 1.750 .000 y 2.200.000 hectolitros (para una población de 1,2 millones de personas). Harris (2011: 165 y 289) usando la misma hipótesis que Tchernia, determinó una cantidad de 1,5 millones 
llegaban a Roma a través de barriles y orcas, cuya importancia en el comercio es difícilmente identificable con certidumbre y que pudieran llegar a la Capital del Imperio (o también a Ostia) desde distintos lugares.

\section{4. \\ Conclusión}

En todas las fases cronológicas analizadas en este estudio, los vinos ibéricos (incluyendo también el defrutum) son minoritarios porque nunca superaron un $10 \%$, aunque durante las épocas trajanea y antonina superen las cantidades de vinos africanos en ambas ciudades (fig. 3). Aunque los vinos ibéricos muestren una disminución constante, no dejan de estar presentes en todas las épocas. También los béticos, a veces, están más presentes que los tarraconenses. Este dato confirma la significativa modificación de la interpretación, que deriva de los datos de Ostia, hecha recientemente por Rizzo (2014b: 403), que establece la imposibilidad de aceptar nada más que la ofrecida por el mismo Rizzo (2003: 215) y por Tchernia (2011:371) que anteriormente veía una disminución de los vinos béticos en Roma desde la época trajanea, porque esta disminución sólo se produce desde la época antonina. Al mismo tiempo, los datos ofrecidos permiten una revaluación de los estudios que suponían una drástica disminución ya sea en la producción, ya sea en la exportación de los vinos tarraconenses desde la época flavia (Dell'Amico, Pallarés, 2007: 122). Lo que no parece poder sustentarse ateniendo a los datos anfóricos en ambas ciudades que ofrecen ánforas tarraconenses

de hectolitros cada año. Mattingly, Aldrete (2000: 154) sugirieron $1.000 .000 \mathrm{hl}$ de vino (100 litros cada persona, cada año). Panella (1985: 190) refiere a otras cifras: entre 1.450 .000 y 1.800 .000 litros cada año. Morley (2007: 577) ha calculado 75.000 litros. Rasmus Brandt (2005: 30-31) se refiere solo a los datos publicados sea por Tchernia, sea por Mattingly y Aldrete, sugiriendo que una mitad de litros era de origen local. 
hasta los finales del II o principios del III siglo d. C. (ánforas tarraconenses han sido halladas en los contextos datados hasta el II siglo d. C. también en los lugares considerados por Bernal Casasola, 2008: 347). Por otra parte, estos datos confirman la gran diferencia entre las dos ciudades estudiadas, dando un testimonio adicional de las diversas direcciones y políticas en el abastecimiento de los alimentos (no solamente vino) originarios en partes diferentes del Imperio en estas dos ciudades (Radae1li, 2018a) o, por el contrario, diferentes gustos o elecciones de orígenes en sus residentes. Efectivamente, los romanos parecen haber sido informados y conscientes de las diferencias y de las calidades de los vinos, relacionándolas a sus orígenes (especialmente las élites como claramente está explicitado por las fuentes antiguas: Radaelli, 2018b: 252). Como ya se ha dicho, los vinos ibéricos raramente son mencionados por sus altas calidades (excepto unos tarraconenses y quizás el defrutum) y las cantidades en Roma son bajas en todas las fases cronológicas consideradas. Por estas razones es posible suponer (sin certidumbre) que los vinos ibéricos estuvieran destinados a ciudadanos que pertenecieran a rangos sociales bajos o medio bajos que quisieran también beber vino, a veces también para evadirse, emulando a la élite (cfr. Radaelli, 2018b: 252 con bibliografía). Probablemente, los que pertenecían a los rangos más bajos elegían los vinos de precio módico porque sus ahorros (que derivaban de salarios adquiridos a través de empleos más o menos temporales o del servicio militar) pudieran permitir que ellos (y sus familias) comprasen solamente productos básicos y baratos (Holleran, 2012: 38). Es siempre muy difícil determinar si los rangos sociales bajos, que podían usar popinae, que siempre han sido fundamentales en las ciudades romanas para encontrar comida caliente y económica y algo para beber, tuvieran decisiones en el consumo. Por una parte, porque las importaciones en Roma siempre eran establecidas por las élites a través de un sistema muy codificado. Por otra parte, porque si un mercado separado existiera con el fin de obtener beneficios económicos, la élite siempre intentaría utilizarlo para incrementar su patrimonio, incluso a través de transacciones de compraventa. Todo ello debido a que las élites 
tenían posesiones de terreno en muchas partes del Imperio que producían productos que eran vendidos en la capital (Radaelli, 2018b: 251 con bibliografía). La presencia de las mencionadas ánforas vinarias originarias de la Península Ibérica en Roma y en Ostia implica que también los vinos ibéricos, aunque pudieran ser de una calidad medio baja (y probablemente baratos), tenían un mercado, ya que una travesía en barco suponía muchos riesgos, lo que viene a indicar que la importación reportaba pingües beneficios ${ }^{19}$. Por esta razón es también posible suponer que ellos viajaran juntos con otros productos como el aceite que siempre era demandado en Roma (y en Ostia) en grandes cantidades. De todos modos, estos vinos llegaban a ambas ciudades porque eran solicitados por algunos ciudadanos que los compraban y los bebían (Radaelli, 2018b: 252), posiblemente gracias a una competitividad de sus precios en los mercados.

\section{Bibliografía}

Ateneo (2008):, Deipnosphistae, Vol. 5: Books VIII-X.420, trad. S. D. Olson. Cambridge, Mass: Loeb Classical Library.

Bernal Casasola, D. (2008): "Vinos Tarraconenses más allá de la columna de Hércules. Primeras evidencias en la Baetica, Lusitania y Tingitana”. En: A. López Mullor, X. Aquilué Abadías (eds.), La producció i el comerç de les àmfores de la Provincia Hispania Tarraconensis: homenatge a Ricard Pascual i Guasch. Barcelona: Museu d'Arqueologia de Catalunya, 319-352.

Bertoldi, T. (2011): “Le anfore”. En: A. Capodiferro, P. Quaranta (eds.), Alle Pendici dell'Aventino, Gliscavi di Via Marmorata 2. Milano: Electa, 148-170.

Brun, J.-P. (1997): "Production de l'huile et du vin en Lusitanie Romaine". Conimbriga, XXXVI: 45-72.

Brun, J.-P. (2003): Le vin et l'huile dans la Mediterranée antique. Viticulture, oléiculture et procédés de transformation. Paris: Errande.

19 No sólo aquellos ibéricos: también otros vinos pueden ser asimilados a esta hipótesis, como aquellos producidos en el valle del Tíber en Italia que eran transportados a lo largo del río (Radaelli, 2016: 85). 
Brun, J.-P. (2004): Archéologie du vin et de l'huile dans l'Empire Romain. Paris: Errande.

Carreras Monfort, C. (2010): "4.3 A Case study of Haltern 70 amphorae”. En: C. Carreras, R. Morais (eds.), The Western Roman Atlantic Façade. A study of the economy and trade in the Mar Exterior from the Republic to the Principate (BAR, Int. Ser., 2162). Oxford: Archaeopress, 201-211.

Carreras Monfort, C., Aguilera, A. (2004): “El producte envasat”. En: C. Carreras Monfort, X. Aquilué Abadías (eds.), Culip VIII i les àmfores Haltern 70. Girona: Museu d'Arqueologia de Catalunya, Centre d'Arqueologia Subaquàtica de Catalunya, 117-132.

Cerchiai Manodori Sagredo, C. (2013): Nettare di Dioniso. La vite e il vino attraverso le parole degli autori antichi. Roma: L'Erma di Bretschneider.

CIL (1893-): Corpus Inscriptionum Latinarum. Berlin: Weidmann.

Columela (1941): De re rustica, Vol. 1: Books I-IV , trad. H. B. Ash. London: Loeb Classical Library.

Columela (1954): De re rustica, Vol. 2: Books V-IX, trad. E. S. Forster, E. Heffner. London: Loeb Classical Library.

Columela (1955): De re rustica, Vol. 3: Books X-XII and On Trees, trad. E. S. Forster, E. Heffner. London: Loeb Classical Library.

D’Arms, J. H. (1995): "Heavy Drinking and Drunkenness in the Roman World: Four Questions for Historians”. En: O. Murray, M. Tecuşan (eds.), In vino veritas. London: The British School at Rome, 304-317.

Dell'Amico, P., Pallarés, F. (2007): "Le anfore della 'Laietania'. Appunti e riflessioni”. Archaeologia maritima mediterranea: International Journal on Underwater Archaeology 4: 53-133.

Estrabón (1966): Geographia, Vol. 2: Livres III-IV, trad. F. Lasserre. Paris: Les Belles Lettres.

Étienne, R. (1975): “À propos du vin pompéien”. En: B. Andreae, H. Kyrieleis (eds.), Neue Forschungen in Pompeji und den anderen vom Vesuvausbruch 79 n. Chr. verschütteten Städten. Recklinghausen: Bongers, 309-316.

Étienne, R., Mayet, F. (2000): Le vin hispanique. Paris: De Boccard.

Floro (2014): Vergilius oratoran poeta, http://www.intratext.com/X/LAT0327.htm.

Frontón (1920): Epistulae de eloquentia ad Antoninum Imp., Vol. II: 302-304, trad. C. R. Haines. London: Loeb Classical Library.

García Vargas, E. (2004a), "Las ánforas del vino bético altoimperial: formas, contenidos y alfares a la luz de algunas novedades arqueológicas". En: D. Bernal, L. Lagostena (eds.), "Figlinae Baeticae”: talleres alfareros y pro- 
ducciones cerámicas en la Bética romana, s. Il a. C. - VII d. C. (BAR, Int. Ser., 1266). Oxford, Archaeopress: 507-514.

García Vargas, E. (2004b), "El vino de la Bética altoimperial y las ánforas. A propósito de algunas novedades epigráficas”. Gallaecia 23: 117-134.

Giacchero, M. (1974): Edictum Diocletiani et collegarum de pretiis rerum venalium: in integrum fere restitutum e Latinis Graecisque fragmentis. Genova: Istituto di Storia Antica e Scienze Ausiliarie.

Harris, W. V. (2011): Rome's Imperial Economy. Twelve essays. Oxford: Oxford University Pess.

Holleran, C. (2012): Shopping in Ancient Rome. The Retail Trade in the Late Republic and Early Principate. Oxford: Oxford University Press.

Juvenal (1959): Saturae, ed. W. V. Clausen. Oxford: Clarendon Press.

López Mullor, A., Martín Menéndez, A. (2008): "Las ánforas de la Tarraconense”. En: D. Bernal Casasola, A. Ribera, I. Lacomba (eds.), Cerámicas hispanorromanas. Un estado de la cuestión. Cádiz: Servicio de Publicaciones de la Universidad de Cádiz, 689-724.

Marcial (1976) : Epigrammaton libri de spectaculis, eds. W. Heraeus, J. Borovskij. Leipzig: Teubner.

Marlière, E., Parrilla, Á. M., Torres Costa, J. (2016): “Rvbrvm, piperatvm et servilianvm. Algunos vinos y preparados vinarios consumidos en Ebvsvs". En: R. Járrega, P. Berni (eds.), Amphorae ex Hispania: paisajes de producción y consumo. Tarragona: Instituto Catalán de Arqueología Clásica, 407-422.

Mattingly, D. J., Aldrete, G. (2000): "The feeding of imperial Rome: the mechanics of food supply system". En: J. Coulston, H. Hodges (eds.), Ancient Rome. The Archaeology of the Eternal City. Oxford: Oxford University School of Archaeology, 142-165.

Maurimon Ribas, P. (2009): “El vi: cultura a l'antiguitat balear”. Historica.cat 1: 1-15, http://ceipac.ub.edu/biblio/Data/A/0553.pdf [19.06.2018].

Morley, N. (2007): "The early Roman Empire: Distribution”. En: W. Scheidel, I. Morris, R. Saller (eds.), The Cabridge Economic History of the Graeco-Roman World. Cambridge: Cambridge University Press, 570-591.

Paladio (1898): Opus Agriculturae, ed. J. C. Schmit. Leipzig: Teubner.

Panella, C. (1985): "I commerci di Roma e di Ostia in età imperiale (secoli I-III): le derrate alimentari”. Misurare la terra. Centuriazione e coloni nel mondo Romano. Città, agricoltura, commercio: materiali da Roma e dal suburbio. Modena: Panini, 180-189. 
Peña, J. T. (2007): Roman Pottery in the Archaeological Record. New York: Cambridge University Press.

Peña Cervantes, Y. (2011/2012): “Variantes tecnológicas hispanas en los procesos de elaboración de vino y aceite en época Romana”. En: J. M. Noguera, J. A. Antolinos Marín (eds.), De vino et oleo Hispaniae: Áreas de producción y procesos tecnológicos del vino y el aceite en la Hispania Romana. Murcia: Universidad de Murcia, 37-57.

Plinio el Joven (1963a): Epistulae, Vol. 1: Books I-VII, trad. B. Radice. London: Loeb Classical Library.

Plinio el Joven (1963b): Epistulae, Vol. 2: Books VIII-X, trad. B. Radice. London: Loeb Classical Library.

Polibio (2012): Histories, Vol. 6: Books XXVIII-XXXIX, trad. S. Douglas Olson. London: Loeb Classical Library.

Publius Ovidius Nasón (1958): Ars Amatoria, trad. E. Barelli. Milano: Rizzoli.

Radaelli, E. (2013): "Un riempimento fognario di età severiana dalle cosiddette 'Terme di Elagabalo' a Roma”. En: E. C. De Sena (ed.), The Roman Empire during the Severan Dynasty: Case Studies in History, Art, Architecture, Economy and Literature (American Journal of Ancient History, 6-8). Piscataway: Gorgias Press, 301-340.

Radaelli, E. (2016): "The so-called 'crisis of the $2^{\text {nd }}$ century AD'. Reflections from the remains of wine-amphorae discovered in the 'Terme di Elagabalo' (Rome)". Emergence. Humanities Graduate School Research Journal VII: Construction and Decay, 79-90.

Radaelli, E. (2017): "Salse di pesce a Roma in età medio imperiale. Considerazioni dai ritrovamenti anforici presso le cd. 'Terme di Elagabalo'”. En: A. Pontrandolfo, M. Scafuro (eds.), Dialoghi sull'Archeologia della Magna Grecia e del Mediterraneo, Atti del I Convegno Internazionale di Studi, Vol. IV. Paestum: Pandemos s.r.l., 1043-1052.

Radaelli, E. (2018a): "Los alimentos (vino y dátiles) de Palestina y Líbano en Roma y en Ostia durante el medio imperio (siglos II - principios del III d. C.): análisis de datos que derivan de las ánforas. En: M. Andrés Chaín, A. M. Gutiérrez Hernández, P. Ortega Martínez, P. Poveda Arias (eds.), La Alimentación en la Historia. Salamanca: Ediciones Universidad de Salamanca, 127-140.

Radaelli, E. (2018b): "The presence of North-African wines in Rome and Ostia during the Middle Imperial age ( $2^{\text {nd }}$-early $3^{\text {rd }}$ centuries AD)". Antesteria. Debates de Historia Antiqua 7: 245-262. 
Ramon Torres, J. (2008): “Les àmfores altimperials d’Ebusus”. En: A. Albert López Mullor, X. Aquilué Abadías (eds.), La producció i el comerç de les àmfores de la Provincia Hispania Tarraconensis: homenatge a Ricard Pascual i Guasch. Barcelona: Museu d'Arqueologia de Catalunya, 241-270.

Rasmus Brandt, J. (2005): “'The Warehouse of the World'. A Comment on Rome's Supply Chain during the Empire". Orizzonti. Rassegna di Archeologia 6: 25-47.

Revilla Calvo, V. (2008): "La producción anfórica en el sector meridional de Cataluña: prácticas artesanales, viticultura y representaciones culturales”. En: A. López Mullor, X. Aquilué Abadías (eds.), La producció i el comerç de les àmfores de la Provincia Hispania Tarraconensis: homenatge a Ricard Pascual i Guasch. Barcelona: Museu D’Arqueologia de Catalunya, 189-226.

Rizzo, G. (2003): Instrumenta urbis I. Ceramiche fini da mensa, Lucerne ed anfore a Roma nei primi due secoli dell'impero. Roma: École Française de Rome.

Rizzo, G. (2014a): “Le anfore dell'area NE”. Studi miscellanei 38 (Ostia VI): 73-370.

Rizzo, G. (2014b): “Ostia, le anfore e i commerci”. Studi miscellanei 38 (Ostia $V I): 393-431$.

Saguì, L., Cante, M. (2015): “Archeologia e architettura nell'area delle 'Terme di Elagabalo' alle pendici nord-orientali del Palatino. Dagli isolati giulio-claudii alla chiesa paleocristiana". THIASOS, Rivista di archeologia e architettura antica 4: 37-75.

Silio Itálico (1934a): Punicorum libri septemdecim, Vol. 1: Books I-VIII, trad. J. D. Duff. London: Loeb Classical Library.

Silio Itálico (1934b): Punicorum libri septemdecim, Vol. 2: Books XIX-XVII, trad. J. D. Duff. London: Loeb Classical Library.

Tchernia, M. A. (1986): Le vin de l'Italie romaine: essai d'histoire économique d'après les amphores. Roma: École Française de Rome.

Tchernia, M. A. (2011): "Subsistances à Rome: problèmes de quantification". En: A. Tchernia, Les Romains et le Commerce. Naples: Centre J. Bérard, 247-262.

Thurmond, D. L. (2006): A handbook of Food Processing in Classical Rome. From Her Bounty No Winter. Leiden/Boston: Brill.

Varón (1978): De re rustica, Vol. 1: Book I, trad. J. Heurgon. Paris: Les Belles Lettres. 